\section{Los primeros veinte años de la radio en el Perú}

\author{
Emilio Bustamante
}

E presente artículo se basa en el primer informe presentado por el autor al Instituto de Investigación de la Universidad de Lima sobre la historia de la radio en el Perú, como parte de un trabajo de investigación referido a la historia de los medios en el país, en el que participan varios profesores de la Facultad de Comunicación. El texto que sigue abarca el período 1925-1945, desde la inauguración de OAX, la primera emisora radial bajo la dictadura de Augusto B. Leguía, hasta el final del primer gobierno de Manuel Prado. El desarrollo del medio radial ha sido considerado en relación con las variables de propiedad, Estado, programación, recepción y géneros.

\section{Propiedad}

La separación entre radiodifusión y radiotelegrafía se establece con claridad después de la Primera Guerra Mundial. Es también por entonces que empiezan a perfilarse modelos de radiodifusión. En Estados Unidos se elige un modelo privado, según el cual el Estado concede licencias de funcionamiento y atribuye frecuencias para uso comercial a empresas privadas. En Europa se experimentan modelos distintos. Francia aplica, en una primera instancia, un régimen mixto; en España se impone un monopolio privado de hecho. A finales de la década de los veinte algunos países europeos (Inglaterra entre ellos) perfilan el modelo de radio pública, 
que contempla la reserva por parte del Estado de frecuencias que son administradas por entidades de derecho público, y la orientación de la programación hacia la educación y la cultura. En el Perú se opta, inicialmente, por un modelo de monopolio privado.

\section{El contrato con la Marconi's Wireless Telegraph Company}

El gobierno de Augusto B. Leguía había decretado, el 19 de enero de 1921, que los servicios de correo, telégrafos y similares (lo que incluía a la radiotelefonía, que era como entonces se llamaba a la radiodifusión) constituían un monopolio cuya explotación corría a cargo del Estado; sin embargo, ese mismo año el gobierno suscribió un contrato con la empresa Marconi's Wireless Telegraph Company, por el que le entregaba a ella "la administración completa, exclusiva e irrevocable, por un período de veinticinco años" de esos servicios, otorgándole facultades para usar y explotar todas sus patentes (presentes y futuras) sobre radiotelegrafía y radiotelefonía. El contrato, elevado a escritura pública el 13 de junio de 1921, fue muy cuestionado, especialmente por los diarios El Comercio y El Tiempo. Cediendo a la presión de los medios y de la oposición política, el Ejecutivo llevó el documento al Congreso para su discusión. Finalmente fue aprobado con algunas modificaciones por ley en $1926 .{ }^{1}$

\section{La Peruvian Broadcasting Company y la primera estación: OAX}

En 1924 se creó la Peruvian Broadcasting Company, con el objeto de "explotar el negocio de la radiodifusión telefónica en toda la República del Perú", según su acta de constitución. La flamante empresa logró que el gobierno le permitiera - por resolución suprema- la adquisición de los derechos y concesiones de la Marconi's Wireless respecto de la "radiotelefonía", de forma tal que se convirtió en "la explotadora exclusiva de aquel negocio", con derechos sobre la importación, venta y alquiler de aparatos para la recepción y la transmisión de radiotelefonía. Los fundadores de la Peruvian Broadcasting Co. fueron los señores César Coloma, Santiago Acuña, Fernando Carvajal, Luis Tirado (peruanos), Paul Widmer (belga), Ronald M. J. Gordon (inglés) y W. F. Ford (estadounidense). Ellos se propusieron crear la primera estación de radio del país, que recibiría la denominación OAX.

1 GARgureviCH, Juan. La Peruvian Broadcasting Co. Historia de la radio (I), 1995, pp. $46-52$. 
Por entonces la dictadura de Leguía invocaba la construcción de la Patria Nueva y pregonaba su fe en la modernidad. La ciudad se transformaba, se inauguraban plazas y avenidas, la radiotelefonía surgía como fenómeno urbano y símbolo de progreso, y compartía espacios en diarios y revistas limeños con otras actividades "modernas" como la aeronáutica, el cine y el fútbol.

En Lima ya existía un grupo de radioaficionados que acogieron con entusiasmo la noticia de que se iba a establecer una estación radial en la ciudad. En días y meses previos a la primera emisión oficial de OAX, El Comercio, La Crónica y Variedades desplegaron nutrida información sobre el nuevo medio.

El 20 de junio de 1925 OAX es inaugurada por Leguía y empieza a emitir programación. Funciona en un local ubicado en la calle Washington, con un equipo similar al del 2LO de Inglaterra.

El entusiasmo que generó la inauguración de OAX duró poco. Al parecer, la venta de receptores (principal fuente de financiamiento de la empresa, ante la falta de publicidad pagada) no prosperó. La sección "Radio" de El Comercio daba cuenta, apenas al día siguiente de inaugurada la emisora, de que muchos lectores se quejaban de los precios impuestos por la Peruvian Broadcasting Co., y explicaba "cómo se puede construir con poco gasto un receptor de cristal". La programación de la emisora, de otro lado, compuesta en su mayoría por música clásica y conferencias culturales, no resultó muy atractiva para un público numeroso. Tampoco la licencia para elevar una antena, que se fijó en una libra peruana.

En setiembre de 1926 la Peruvian Broadcasting Co. anunció su disolución y liquidación. El gobierno dispuso la adquisición de todos los derechos y propiedades de la empresa, y entregó los servicios de radiodifusión a la Marconi's Wireless para su administración. Asimismo, dejó sin efecto la exclusividad concedida a la Peruvian Broadcasting Co. para la importación de aparatos y accesorios radiofónicos, dando cabida a la libre importación. Por último, mediante resolución suprema estableció el pago semestral de una libra peruana por derecho de receptor, anulando las licencias para el uso de receptores emitidas anteriormente. Si bien la libre importación de receptores y artefactos pudo alentar una mayor difusión de la radio en el país, el pago semestral del llamado "derecho de antena" no favoreció el aumento del consumo.

\section{OAX después de la caída de Leguía}

La recesión mundial tuvo efectos devastadores en la economía del Perú y precipitó la caída de Leguía, quien fue derrocado en agosto de 1930. El 1 de octubre, la Junta Militar que se hizo 
del poder dispuso, mediante resolución suprema, que el Ministerio de Gobierno asumiera directamente la administración del servicio de radiodifusión, nombrando al señor Joaquín de Azambuja como jefe de dicho servicio. Al año siguiente la OAX fue puesta bajo la administración de una nueva empresa privada, la Compañía Nacional de Radiodifusión, fundada por Guillermo Lazarte, Santiago Neguib y Félix Navarro. La Marconi protestó y entabló pleito al Estado peruano invocando el contrato firmado con el gobierno de Leguía. El contrato fue revisado y rescindido por la ley 7576 del Congreso Constituyente en setiembre de 1932, pero el conflicto con la Marconi duraría hasta 1935.

El retiro forzado de la Marconi abrió las puertas al otorgamiento de licencias a otras empresas privadas. El consumo de la radio, sin embargo, era mínimo y se mantuvo así durante la grave crisis económica y política que sufrió el país entre 1930 y 1933.

\section{Nuevas estaciones privadas}

Bajo el efecto de la crisis mundial, hacia 1931 el Estado peruano había quedado en bancarrota financiera, el comercio se contrajo, la moneda se devaluó, se restringió el crédito y aumentó la desocupación. La violencia política alcanzó sus topes con la insurrección aprista de Trujillo en 1932 y el asesinato del presidente Sánchez Cerro en 1933.

No obstante, ese mismo año de 1933 hubo signos de recuperación económica (gracias al aumento del precio del algodón) y para 1934 el país estaba ya superando la crisis. Un indicativo de ello fue la aparición de nuevas emisoras radiales de carácter privado: $\mathrm{OAX} 4 \mathrm{~B}$ Radio Grellaud (del ingeniero Roberto Grellaud, más tarde Radio Lima), OAX4C Radio Dusa (Difusora Universal S.A. de Carlos y Jorge Franco), OAX4E Radio Weston (que después se llamaría Radio Goicochea y más tarde Radio Central, propiedad del ingeniero Juan Pablo Goicochea). En 1935 surgieron OAX4I Radio Internacional (de Antonio Vásquez Pequeño), OAX4L Radio Miraflores (de los hermanos Clemente y Ricardo Palma), Radio Sucre, OAX4F Radio Castellano, OAX4H Radio Dávila y OAX4T Radio Gilco. Los propietarios de las tres últimas eran concesionarios de fabricantes de aparatos receptores en el Perú, y llenaban su programación con música grabada en discos que vendían en sus respectivos establecimientos. Ante la aparición de las nuevas emisoras, la antigua OAX empezó a denominarse OAX4A Estación Radiodifusora Nacional.

\section{Creación de Radio Nacional del Perú}

En 1935 el gobierno y la Marconi hicieron las paces. El Estado cedió nueva- 
mente a la Marconi la administración de las comunicaciones en el país, a cambio de que esta donara una moderna estación radial que reemplazara a la antigua OAX. Así, se relanzó la emisora del Estado con el nombre de Radio Nacional del Perú. En enero de 1937 se inauguraron los nuevos equipos y locales con asistencia del presidente Benavides y el representante de la Marconi, Miguel McNulty, quien fue nombrado gerente de la emisora. Las oficinas y estudios de Radio Nacional del Perú se ubican desde entonces en la avenida Petit Thouars. El Estado asumió la administración directa de la estación.

El mismo año de 1937 el gobierno de Benavides promulgó un Reglamento de Radiodifusión y consagró así un modelo en el que, reservándose una potente emisora, admitía el otorgamiento de licencias a empresas privadas de radiodifusión comercial.

\section{La primera cadena privada}

A comienzos de los cuarenta algunas emisoras desaparecen (Radio Castellano, Radio Dávila, Radio Sucre), pero otras son inauguradas. Radio Mundial, de Tomás Ronald, sale al aire el 23 de enero de 1942. Su director es Juan Sedó, quien ya había destacado como locutor deportivo de Radio Nacional. La estación trae de Argentina a Alberto Pillado Matheu como gerente de pro- ducción y a su esposa, la actriz y escritora Queca Herrero (María Angélica Herrero), quien años después tendría notable participación en varias emisoras peruanas.

En 1942 se crea la primera cadena privada: la Compañía Peruana de Radiodifusión S.A., de propiedad de José Bolívar, Jorge Cárcovich y Antonio Umbert. La cadena comprende a Radio Lima, Radio América, Radio Callao, Radio Miraflores y Radio Goicochea en Lima, Radio Delcar de Chiclayo, Radio Universal de Ica, Radio Continental de Arequipa, Radio Huancayo, Radio Huánuco y Radio Cusco. La Compañía Peruana de Radiodifusión S.A. se llama a sí misma, con orgullo, "la organización de radio más poderosa de la costa del Pacífico Sur".

Las principales emisoras de la cadena son Radio Lima y Radio América. Radio Miraflores y Radio Callao se separan al poco tiempo de la red. Radio Goicochea hace lo mismo, y su propietario, Juan Pablo Goicochea, cede las riendas de la emisora a Genaro Delgado Brandt y Alberto Pillado Matheu; ambos asumen la dirección en noviembre de 1942 .

En 1944, Bolívar y Cárcovich se retiran de la Compañía Peruana de Radiodifusión S.A. Radio América pasa a ser propiedad de Antonio Umbert y Nicanor González Vásquez; y Radio Lima es comprada por los hermanos Aveli- 
no, Luis y Raúl Aramburú. ${ }^{2}$ Ese mismo año sale al aire Radio Victoria, de José Eduardo Cavero, que más tarde se convertirá en la cabeza de la mayor cadena radial privada del país.

\section{El Estado y la radio}

El Estado promovió la comunicación radial desde comienzos del siglo $\mathrm{XX}$, bajo la forma de radiotelegrafía, al parecer dentro de una política modernizadora que pretendía la integración del país y sobre todo de la Amazonía a la capital, en una coyuntura de definición de fronteras geográficas.

En enero de 1921, invocando razones de seguridad nacional, el gobierno de Leguía consideró, mediante decreto supremo, que "los sistemas de telegrafía y telefonía sin hilos" debían ser monopolizados por el Estado. ${ }^{3}$ Sin embargo, pocos meses después contempló que el desarrollo de esos medios de comunicación demandaba inversiones que excedían su capacidad financiera y entregó su administración a la Marconi. La tesis de Gargurevich ${ }^{4}$ según la cual la Peruvian Broadcasting Co. estaba integrada por amigos del presidente es atendible, pero no está demostrada, aunque la empresa obviamente contó con la complacencia del gobierno y de la Marconi. El uso político que el régimen pudo dar a la radiodifusión fue, sin embargo, muy limitado.

Si bien Leguía, al inaugurar OAX, llamó a los ciudadanos a participar en el plebiscito sobre la cuestión de Tacna y Arica, el discurso en realidad estaba dirigido a la prensa y no a los oyentes, como lo reconoce el mismo Gargurevich, ${ }^{5}$ pues el número de receptores era aún muy escaso. OAX retransmitió también los discursos presidenciales ante el Congreso en las fiestas patrias de 1927.

Como ya hemos señalado, cuando cae el gobierno de Leguía el contrato con la Marconi es rechazado por el nuevo gobierno. La administración de la radio OAX pasa a otra empresa privada tras una brevísima administración estatal. Al dejarse de lado el monopolio estatal y privado (aunque en la práctica exista aún una sola emisora), el Estado considera imponer su control sobre los contenidos de los mensajes radiofónicos. La Ley de Imprenta 6961 del 2 de diciembre de 1931 contempla la posibilidad y sanción de delitos cometidos a

2 ALEGría, Alonso O.A.X. Crónica de la radio en el Perú (1925-1990), 1993, p. 102.

3 GARGUREVICH, Juan. Op. cit., p. 54.

4 Ibídem.

5 Ibídem, p. 81. 
través de la radio; algunos de estos delitos son: difamación, injuria, calumnia y provocación al homicidio, robo, incendio, lucha armada o guerra. ${ }^{6}$

En enero de 1936, la dictadura de Benavides intervino con una investigación a Radio Sucre por la emisión de "propaganda subversiva" atribuida a asaltantes que habían tomado esa emisora. El asalto, como lo recuerda Armando Villanueva del Campo en sus memorias, $^{7}$ fue planeado y ejecutado por un comando del Partido Aprista, por entonces proscrito. Ese mismo año el gobierno decretó el cierre del programa La revista oral que conducía César Miró en Radio Dusa, por emitir un pronunciamiento del candidato presidencial José Antonio Eguiguren, quien se presentaba a las elecciones con apoyo aprista. ${ }^{8}$ Como se sabe, Eguiguren ganó las elecciones pero estas fueron anuladas. En 1937 el Estado asumió directamente la administración de OAX con el relanzamiento de Radio Nacional.

La refundación de Radio Nacional y la publicación de un Reglamento de radiodifusión, también en 1937, implicaron el reconocimiento por el Estado de la importancia que había adquirido el medio, al punto de que consideraba que merecía una regulación específica y podía ser usado por el gobierno con fines de propaganda y de "afirmación de lo nacional".?

Al respecto, debe tomarse en cuenta la coyuntura política externa como la interna. En política exterior las tensiones con Colombia y Ecuador; y en política interna con el Apra y el comunismo. El pretexto que esgrimió el gobierno de Benavides para anular las elecciones que ganó José Antonio Eguiguren fue que habían votado en ellas ciudadanos que respondían a consignas de partidos extranjeros. La propaganda que el régimen proponía a través de la radio estaba dirigida parcialmente hacia afuera, pero fundamentalmente hacia dentro del país; buscaba llegar a la masa urbana interna, afirmando "lo nacional" en contra de corrientes, no solo artísticas sino también políticas, que eran catalogadas de extranjerizantes.

Lo "nacional" en la radio se vinculó al costumbrismo y a las manifestaciones de lo "popular": en primer lugar la música criolla de la costa, y en menor medida la música andina. Se trataba con ello de ganar a las masas populares a las posiciones políticas del go-

\footnotetext{
6 PERLA ANAYA. José. La radiotelevisión. Espectro del poder y del futuro, 1995, pp. 48-49.

7 VILLANUEVA, Armando y Guillermo THORNDIKE. La gran persecución, 2004, pp. 75-77.

8 ALEGría, Alonso. Op. cit., p. 58.

9 PERLA ANAYA, José. Op. cit., pp. 49-50.
} 
bierno (y alejarlas de la influencia subversiva del Apra y el comunismo) mediante el reconocimiento de su cultura, que se llevaba a cabo al mismo tiempo que se le otorgaban beneficios laborales y atención social.

Benavides utilizó la radio para dirigir mensajes a la nación, tanto en las festividades patrias como a fin de año. En el discurso de fin de año de 1934 dijo: "No es un discurso el que voy a pronunciar; es una charla amistosa con mis conciudadanos, en estilo tan llano, preciso y claro como me sea posible". ${ }^{10}$ El tono recuerda a las "charlas junto al fuego" que el presidente norteamericano Roosevelt dirigía a los oyentes de su país entre 1933 y 1936. En cualquier caso, Benavides fue el primer jefe de Estado peruano que empleó de modo regular y consciente la radio como medio masivo con una orientación claramente política.

La propaganda de lo "nacional" en la radio, promovida por el Estado, no era necesariamente explícita. Pudieron influir en su concepción las emisiones diarias que se recibían en Lima de Radio Berlín, y que se prolongaron inclusive después de estallada la Segunda Guerra Mundial. Radio Berlín emitía música clásica de autores alemanes, pero también música folclórica y canciones populares, aparte de noticieros tendenciosos. Su programación aparecía en el diario El Comercio y en las revistas Voces en Ondas y Alta Voz, entre otros medios.

Cabe mencionar, además, que la política económica del régimen de Benavides apuntó a respaldar al sector industrial de la economía, lo que benefició a los nuevos empresarios radiales. ${ }^{11}$

El gobierno de Manuel Prado (19391945), por su parte, buscó remarcar el sesgo educativo que el Estado pretendía dar al medio, creando la Escuela Nacional del Aire para "auxiliar el dictado de las lecciones escolares y crear núcleos especiales de alumnos entre el elemento obrero y campesino", según discurso del presidente en 1944; ${ }^{12}$ abocándose Radio Nacional, por entonces bajo la dirección artística de César Miró, a irradiar radioteatros culturales con Augusto Tamayo Vargas y Alberto Tauro como libretistas.

Prado, un miembro de la oligarquía que había llegado al gobierno con votos apristas y comunistas, se mostró bastante tolerante con la sindicalización de los trabajadores. El presidente acudió en diciembre de 1942 a la pro-

10 El Comercio, 1 de enero de 1935, p. 4.

11 Cf. CARAVEDO, Baltazar. Burguesía e industria en el Perú, 1933-1945, 1976.

12 El Comercio, 29 de julio de 1944, p. 8. 
clamación de la Asociación Mutualista de Artistas y Empleados de la Radio (Amaer) que tuvo lugar en el Teatro Segura.

No obstante, un episodio ocurrido durante el régimen, y cuya investigación se ha de profundizar, es el cierre de Radio Internacional. Alegría ${ }^{13}$ dice que el Estado retiró la licencia a dicha empresa acusando al director de la radio, el español Antonio Vásquez Pequeño, de ser partidario de las fuerzas del Eje. Como se sabe, el Perú respaldaba a los aliados en la Segunda Guerra Mundial. La versión es corroborada por Maruja Venegas, ${ }^{14}$ empleada de la emisora por entonces, quien adjudica el cierre de Radio Internacional a "problemas de política peruana y la guerra", pues "Vásquez Pequeño era germanófilo”. Radio Internacional pasó a otros dueños con el nombre de Radio Colonial, y, finalmente, en los cincuenta, se convirtió en Radio La Crónica, de propiedad de la familia Prado.

\section{Programación y recepción}

La programación de OAX (prácticamente la única emisora entre 1925 y
1934) estaba orientada hacia un público escaso y de élite (aquel que podía comprar un receptor y pagar el derecho de antena). Tal programación no tenía únicamente un contenido educativo e informativo, pues los directores artísticos de la emisora (Antonio Garland y Rosa Hernando) alternaban la lírica, la música clásica, las conferencias culturales, las clases de inglés y las noticias sobre cotizaciones, lotería y boticas, con monólogos cómicos, one steps, fox trots, tangos y pasodobles.

Sin embargo, ese público de élite no constituía un mercado suficiente para una radiodifusión comercial. Cuando a partir de 1934 aparecieron nuevas emisoras, voceros de ese público instruido y económicamente solvente, como el crítico musical Carlos Raygada, se quejarían de que los cantantes líricos que asistían a las emisiones en vivo no tenían la calidad de los intérpretes de los discos importados; ${ }^{15}$ la misma observación haría un anónimo editorialista de la revista Voces en Ondas, pero para demandar que las emisoras irradiaran menos música selecta y más música popular. ${ }^{16}$ Para entonces la mejora de la tecnología y la superación de la crisis permitieron que los sectores menos favore-

13 ALEGRÍA, Alonso. Op. cit.

14 Entrevista del 22 de enero del 2004.

15 RAYGADA, Carlos. "El año artístico y musical". El Comercio, Lima, 2 de enero de 1938, edición de la mañana, p. 14.

16 Revista Voces en Ondas 2, p. 4. 
cidos pudieran adquirir receptores baratos, a plazos y de mayor calidad. Ello facilitó lo que sería el fenómeno más importante de la década: el acceso de la cultura popular al medio y su conversión en masivo.

El agitado proceso electoral de 1931 había tenido como particularidad la intervención de grandes movimientos de masas. Por primera vez en la historia del Perú las masas populares habían hecho su aparición como actores políticos con claras demandas. Después del asesinato del presidente Sánchez Cerro, el gobierno del general Benavides trató de frenar la presión social a través de medidas represivas, pero también pretendió satisfacer parte de esas demandas vía el gasto público en la generación de puestos de trabajo y el otorgamiento de beneficios laborales. Fueron creados los ministerios de Educación y Salud, se estableció el Seguro Social Obligatorio y se inauguraron los restaurantes populares. ${ }^{17}$ Las masas, que empezaban a tener influencia en la política y los planes sociales del Estado, también hicieron sentir su presencia en los medios de comunicación, concretamente en la radio. Como hemos señalado, el gobierno concibió la radio como un instrumento de propaganda de lo nacional. Admitió las manifesta- ciones de la cultura popular, en especial la música, como parte de lo nacional, buscando de este modo el reconocimiento de esas masas populares (es decir, que lo identificaran como "su" gobierno), a la vez que procuraba alejarlas de la influencia política de agrupaciones cuya ideología catalogaba de "foránea".

Los empresarios privados, por su parte, orientaron decididamente el medio hacia el entretenimiento. No obstante cabe indicar que los objetivos culturales y de propaganda del gobierno de Benavides no estaban reñidos con los objetivos comerciales de los empresarios peruanos. Si para el gobierno emitir música popular peruana contribuía a afirmar la nacionalidad y facilitaba la hegemonía de los sectores dominantes, para los empresarios era sencillamente rentable, pues esa música era la preferida de la mayoría de los oyentes. El mercado se iba ampliando y aparecían los anunciantes ávidos de captar compradores, si no demasiado solventes, sí bastante numerosos. De este modo, fuera por afán de lucro o por política gubernamental, por primera vez asomaba lo popular como parte de la cultura nacional en un medio masivo.

17 CARAVEDO, Baltazar. Op. cit. y PORTOCARRERO M., Gonzalo. De Bustamante a Odría. El fracaso del Frente Democrático Nacional 1945-1950, 1983. 
La celebridad de los artistas de la radio se incrementó y la demanda del público por espectarlos en vivo originó la presentación de ellos en teatros y cines de barrio. A fines de los treinta y comienzos de los cuarenta, emisoras como Lima, América, Goicochea y Central inauguraron auditorios. Radio Nacional no se quedó atrás y, bajo la dirección de César Miró, construyó, durante el primer gobierno de Prado, un auditorio a partir de uno de los estudios del local de Petit Thouars.

\section{Géneros}

Los géneros radiales funcionaron adecuadamente como mediadores desde fines de los años treinta, logrando la identificación y el reconocimiento de los sectores populares en sus mensajes.

En cuanto a las preferencias del público por determinados géneros, una encuesta promovida por el diario $L a$ Crónica y Radio Central en 1944 confirmó la predilección por la música criolla y los radioteatros. ${ }^{18}$

\section{Programas musicales}

Aunque la música "ligera" nunca estuvo ausente de la programación de OAX en los diez primeros años de la radiodifusión en el Perú, a partir de
1935 se observó un aumento de la música bailable y popular. Emisoras como Radio Dusa y Radio Goicochea tenían entonces un conjunto de jazz estable y con más frecuencia que antes se escuchaban tangos, rancheras, swings y fox trots.

La música popular costeña (conocida como "música criolla") se dejaba oír tímidamente en los años veinte a través de OAX, gracias al dúo Gamarra-Salerno. En 1934 (en OAX4A Emisora Nacional) y en 1935 (en Radio Goicochea), el grupo Los Criollos interpretaba valses peruanos. Pocos años más tarde la música criolla empezó a extenderse a todas las emisoras limeñas. Si bien desde los años veinte este tipo de música había experimentado un renacimiento gracias a una generación de compositores encabezada por Felipe Pinglo (18991936), su acceso a la radio fue reducido, hasta que a partir de 1937 contó con el respaldo del Estado y de los propietarios de las nuevas emisoras privadas.

La música popular peruana alcanzó en adelante muchísima notoriedad. Entre los intérpretes de música criolla más celebrados, que se presentaban en vivo en las emisoras, destacaron: La Limeñita, Jesús Vásquez, Las Costeñitas, Las Estrellitas, Yolanda Matos, Maruja

18 Cf. VARGAS ESCALANTE, Jorge y Enrique M. GAMIO. 40 años de radio en el Perú, 1944, p. 156. 
López, Rosita Delgado, Delia Vallejos, Carlota Calderón, Esther Cornejo, Flora Cevallos, Filomeno Ormeño, Eduardo Márquez Talledo y Pedro Espinel. Los intérpretes de música andina más importantes fueron el Cuarteto de Cámara Incaico de Félix F. Castro, el Conjunto Folklórico Atusparia y el músico Moisés Vivanco, quien hacia 1941 impulsó la carrera de la cantante Ima Sumac.

\section{Noticieros}

Otras novedades de los años treinta fueron los programas noticiosos. En la década de los veinte OAX se limitaba a informar sobre las cotizaciones, los turnos de las boticas y los resultados de la lotería. En 1935 los locutores de Radio Dávila simplemente leían los periódicos del día; Radio Goicochea transmitía las noticias de El Universaly OAX4A las de El Comercio. Pero Radio Dusa tenía ya un servicio exclusivo de la United Press Ass., y en 1936 inauguraba La revista oral, bajo la dirección de César Miró. Desde 1937 Radio Nacional emitió La gaceta del aire en tres horarios, en la voz del locutor Eulogio Rengifo.

En Radio Internacional el argentino Néstor Tato condujo Reloj musical hacia fines de los años treinta, incorporando noticias breves alternadas con notas sobre cine y temas musicales, en un programa que tenía más de revista que de noticiero clásico. ${ }^{19}$

Siguiendo el modelo de Reloj musical, en 1940 Radio Lima estrenó Buenos dias de 7.45 a.m. a 9.15 a.m., programa conducido por Guillermo Lecca Iturbe, Nelson Arrunátegui y Pepe Burgos. Participaban el compositor y pianista Eduardo Pereira y los comediantes Chola Extremaunción, Huachafa Zoila, Don Nicola Malatesta, Julián y Fernandete. Era también una revista matutina que alternaba noticias, comentarios, música y humor. Alta Voz celebraba que fuera "una agradabilísima innovación a la monótona lluvia de noticias" que constituían la mayoría de los programas informativos de entonces. ${ }^{20}$

En 1941 Radio Lima incluyó una revista semejante en horario nocturno con el nombre de Buenas noches. Ese mismo año Radio Goicochea presentó un noticiero matutino de estilo ligero conducido por Enrique Breneissen. ${ }^{21}$

\section{Radioteatros}

Radio Goicochea transmitía en diciembre de 1935 una comedia en tres actos: La verdad en los ojos, de Pedro E. Picó, con Camila Sánchez, Julia Serrano, Ro-

19 Revista Alta Voz 85, 1 de marzo de 1941, s/p.

20 Op. cit. núm. 74, 14 de diciembre de 1940, s/p.

21 VARGAS ESCALANTE, Jorge y Enrique M. GAMIO. Op. cit 
sa Armida, Alfredo Hernández, Alberto Ego Aguirre y Lucho Muñoz.

Radio Lima comenzó dramatizando episodios históricos en 1937 y en 1938 tuvo radioteatro diario en el que actuaba "El Conjunto Travesí", integrado por Fernando Travesí y sus hijas Gloria, Angelita y Elvira. En 1939 en esa emisora se hicieron dramatizaciones de canciones con libretos de Carlos Gutiérrez y en 1942 se presentó la radionovela La Perricholi de Juan Colich, por el conjunto Evocaciones, que dirigía Mecha Cabot. Hacia 1944, Vargas Escalante consideraba que Radio Lima tenía "el mejor cuadro de comedias en el Perú", 22 el mismo que estaba integrado por los actores: Pepita Ureta, Cucha Miró, Guillermo Lecca Iturbe, José Luis Romero y Luis Canessa.

En Radio Nacional destacaron entre 1938 y 1939 los escritores Juan Malbourg (que adaptaba a Julio Verne para niños) y Jorge Rivarola (con obras originales para espacios como 30 minutos de bistoria y Esto sucedió ayer). Actuaban, entre otros, Pedro Ureta, Juan Ureta y Rosa Elvira Figueroa, quien oficiaba de directora. También en Radio Nacional se presentaban por esos mismos años comedias a cargo del grupo dirigido por la actriz Columba Quintana.
A partir de 1940, Radio Nacional emitió radioteatros con una orientación educativa; escribían los libretos originales Augusto Tamayo Vargas, Alberto Tauro y Emilio Champion. Así mismo, hubo en la estación del Estado representaciones de clásicos, en las que actuaban Elvira Travesí, Juan Ureta, María Mille y Elvira Tizón; los directores del equipo de radioteatro eran Elvira Tizón y Luis Romero.

A comienzos de los años cuarenta, Radio Central (ex Radio Goicochea) destacó por sus radionovelas dirigidas y protagonizadas por la actriz argentina Queca Herrero.

\section{Concursos}

Los programas de concurso más celebrados de los años treinta eran aquellos que buscaban nuevos artistas. Radio Nacional y Radio Goicochea convocaron a este tipo de certámenes. El músico Moisés Vivanco, con su trío Los Estudiantes, fue uno de los ganadores en 1938. También en Radio Nacional se realizaban concursos para estudiantes auspiciados por la empresa Field. Sin embargo, sería Radio Central la que innovaría el género en la primera mitad de los cuarenta con los programas El chanchito de la inteligencia, Preguntones y respondones, El contra- 
punto radial y Soles por palabras, que produjo Alberto Pillado Matheu. ${ }^{23}$

\section{Humorísticos}

El humor estuvo presente desde los años veinte en los programas de OAX, pero solo en los treinta tuvo exponentes reconocidos por el público con espacios fijos dentro de la programación. La mayor humorista del periodo fue Teresita Arce, "La Chola Purificación Chauca", cuyos monólogos en Radio Nacional (escritos en su mayoría por Marino Ratto) gozaron de gran popularidad. También fueron apreciados Pedro Ureta y el argentino Freddy El Rezongón (Abraham Rubel). En Radio Lima destacaron El Cholo Revolledo y Don Nicola Malatesta dentro del programa La media hora en broma.

\section{Conclusiones}

De acuerdo con lo expuesto hasta aquí, podemos afirmar que:

- En los primeros 20 años de la radio en el Perú se fue gestando, y terminó por consolidarse, un modelo según el cual el Estado otorgaba licencias a empresas privadas para el uso comercial de las frecuencias. Sin embargo, el Estado se reservó también el uso de una frecuencia en la que operaba una poderosa emisora de alcance nacional.

- El empleo político de la radio se acentuó bajo la dictadura del general Óscar R. Benavides, que estableció respecto de ella funciones de propaganda y afirmación de lo nacional. La oposición, y en particular el Partido Aprista, también dio al medio un uso político durante el periodo.

- La radio se convirtió en un medio masivo solo hacia finales de los años treinta. Varios factores lo permitieron, entre ellos la superación de la crisis económica, el abaratamiento de los aparatos receptores, la política populista del régimen de Benavides y la necesidad de los empresarios radiales de ampliar el mercado.

- Los géneros que facilitaron la mediación entre los sectores populares y los grupos fueron especialmente el musical (con evidente énfasis en la música popular de la costa) y el dramático a través de los radioteatros.

\section{Bibliografía}

ALEGRÍA, Alonso. O.A.X. Crónica de la radio en el Perú (1925-1990). Lima: Radioprogramas Editores, 1993.

23 VARGAS ESCALANTE, José y Enrique M. GAMIO. Op. cit. 
BASADRE, Jorge. Historia de la República del Perú. 1822-1933. Tomos XIII y XIV. Lima: Editorial Universitaria, 1970.

BURGA, Manuel y Alberto FLORES GALINDO. Apogeo y crisis de la República Aristocrática. Lima: Ediciones Rikchay Perú, 1980.

CARAVEDO, Baltasar. Burguesía e industria en el Perú, 1933-1945. Lima: Instituto de Estudios Peruanos, 1976.

DERPICH, Wilma; HUIZA, José Luis y Cecilia Israel. Lima años 30. Salarios y costo de vida de la clase trabajadora. Lima: Fundación Friedrich Ebert, 1985.

GARGUREVICH, Juan. La Peruvian Broadcasting Co. Historia de la radio (I). Lima: La Voz Ediciones, 1995.

Ministerio de Hacienda y Comercio. Censo Nacional de Población y Ocupación 1940. Primer volumen. Director: Alberto Arca Parró. Lima, 1944.

PERLA ANAYA, José. La radiotelevisión. Espectro del poder $y$ del futuro. Lima: Universidad de Lima, Publicación del Centro de Investigación en Comunicación Social (Cicosul), 1995.

PORTOCARRERO M., Gonzalo. De Bustamante a Odría. El fracaso del Frente Democrático Nacional 1945-1950. Lima: Mosca Azul Editores, 1983.
QUIJANO, Aníbal. "El Perú en la crisis de los años 30", en Imperialismo, clases sociales y estado en el Perú 1890-1930. Lima: Mosca Azul Editores, 1985.

RAYGADA, Carlos. "El año artístico y musical". El Comercio, Lima 2 de enero de 1938, edición de la mañana, p. 14.

VARGAS ESCALANTE, Jorge. "Los progresos de la radio en el Perú". El Comercio. Lima, 1 de enero de 1938, edición de la mañana.

VARGAS ESCALANTE, Jorge. "Historia de la radio en el Perú a través de los últimos 30 años", en Lima en el IV Centenario de su fundación. Monografia del departamento de Lima. Lima: Editorial Minerva, 1935.

VARGAS ESCALANTE, Jorge y Enrique M. GAMIO. 40 años de radio en el Perú. Lima: Imprenta Lux, 1944.

VILLANUEVA, Armando y Guillermo Thorndike. La gran persecución. Lima: Universidad San Martín de Porres/Empresa Periodística Nacional S.A., 2004.

Diarios: El Comercio y La Crónica.

Revistas: Variedades, Mundial, Voces en Ondas, Alta Voz, Radio Cine, El Cancionero de Lima, La Lira Limeña.

Entrevista: Maruja Venegas (22 de enero del 2004). 